\title{
The C825T polymorphism in the human G-protein $\beta 3$ subunit gene is not associated with diabetic nephropathy in Type I diabetes mellitus
}

\author{
D.G. Fogarty, M.J. Zychma, L.J. Scott, J.H. Warram, A.S. Krolewski \\ Research Division, Joslin Diabetes Center, and Department of Medicine, Harvard Medical School, Boston, USA
}

\begin{abstract}
Summary In Type I (insulin-dependent) diabetes mellitus a genetic predisposition exists to nephropathy and is related to parental hypertension. Enhanced G-protein activation, a cellular phenotype observed in cultured cells from patients with essential hypertension, was recently documented in Type I diabetic subjects with nephropathy. This enhanced G-protein activation has been associated with a genetic variant in the G-protein $\beta 3$ subunit, GNB3. A C $\rightarrow$ T polymorphism at position 825 in exon 10 is associated with Gprotein activation, the $\mathrm{T}$ allele associated with enhanced activity. Furthermore the $\mathrm{T}$ allele was observed more frequently in a group with essential hypertension. In this report we have analysed the role of the C825T polymorphism in the predisposition to diabetic nephropathy in Type I diabetes. We have investigated the frequency of this polymorphism in a large case-control study and found no association of the $\mathrm{T}$ allele with diabetic nephropathy. Specifically carriage of the T allele as CT or TT was observed in
\end{abstract}

$49 \%$ of 200 Type I diabetic control subjects with normoalbuminuria (diabetes duration 24 years) compared with $53 \%$ of 216 Type I diabetic subjects with nephropathy (overt proteinuria or end-stage renal failure). Within this group we have also examined the inheritance of C825T alleles in a family study and found no evidence for excess transmission of the T allele to Type I diabetic offspring with nephropathy ( $\mathrm{T}$ allele transmitted to $51 \%$ of nephropathy offspring, $\mathrm{C}$ allele transmitted to $49 \%$ of nephropathy offspring, $p=0.79$ ). In none of the Type I diabetic datasets examined was there any effect of genotype on variation in systolic or diastolic blood pressure. In conclusion we can find no evidence for the C825T polymorphism of the $\beta 3 \mathrm{G}$-protein subunit as a major gene in the susceptibility to diabetic nephropathy in Type I diabetes. [Diabetologia (1998) 41: 1304-1308]

Keywords Diabetic, nephropathy, susceptibility. GNB3. hypertension, Type I diabetes.
Diabetic nephropathy is the commonest cause of end-stage renal disease (ESRD) in the Western world accounting for $35 \%$ of people currently starting dialysis in the United States [1]. Substantial evidence ex-

Received: 27 April 1998 and in revised form: 9 July 1998

Corresponding author: A. S. Krolewski, M. D., Ph.D, Joslin Diabetes Center, One Joslin Place, Boston, MA 02215, USA Abbreviations: ESRD, End-stage renal disease; PTX, pertussis toxin; NHE, sodium-hydrogen exchange; TDT, transmissiondisequilibrium test; GNB3, guanine nucleotide binding protein beta polypeptide 3; GTP- $\gamma \mathrm{S}$, guanosine triphosphate gamma subunit; SBP, systolic blood pressure; DBP, diastolic blood pressure; ACR, albumin:creatinine ratio. ists to suggest that a proportion of people with diabetes have a genetic predisposition to diabetic nephropathy $[2,3,4]$. Raised arterial blood pressure and hypertension are more prevalent in the parents of offspring with Type I (insulin-dependent) diabetes mellitus and nephropathy than in the parents of Type I diabetic patients without nephropathy $[5,6]$. Therefore familial clustering of diabetic nephropathy could be related to inherited abnormalities of blood pressure regulation.

Increased sodium-hydrogen exchange (NHE) has been documented in many cell types from humans with hypertension and diabetic nephropathy [6-9]. In essential hypertension the basis of this enhanced activity appears to be closely related to increased ac- 
tivation of pertussis toxin (PTX)-sensitive G-proteins which are involved in the modulation and transduction of various transmembrane signalling systems $[10,11]$. Recently enhanced G-protein activation has been shown in immortalized B lymphoblast cell lines from diabetic nephropathy patients compared with matched diabetic patients without nephropathy [12]. The molecular basis of enhanced G-protein activation in a group of hypertensive people, selected for raised NHE activity has also been delineated [13]. Evidence was presented that a C-T polymorphism at position 825 in exon 10 of the gene for the $\beta 3 \mathrm{G}$-protein subunit is associated with altered mRNA splicing and enhanced activity of the protein. Specifically carriage of the $T$ allele is associated with a novel splice variant characterized by a $123 \mathrm{bp}$ in-frame deletion affecting exon 9. Furthermore in cell lines from 5 normotensive and 6 hypertensive people, selected respectively for low or enhanced NHE activity, it was shown that carriage of a T allele is universally associated with enhanced binding of guanosine triphosphate gamma subunit (GTP- $\gamma \mathrm{S})$ to PTX-sensitive Gproteins. Finally in a case-control association study it was shown that the frequency of the $T$ allele is increased in hypertensive compared to normotensive people [13]. Considering these findings, we speculated that this genetic variant, associated with essential hypertension, possibly increases susceptibility to diabetic nephropathy.

Case-control studies are highly effective in detecting any role candidate genes have in susceptibility to complex diseases [14]. The role of candidate genes can also be assessed in family-based association studies [15]. We have recently reported, for the first time, the use of such a family association study in assessing candidate genes in diabetic nephropathy susceptibility [16]. The basis of this study is the transmission disequilibrium test (TDT), a powerful method to assess susceptibility alleles in the causation of polygenic disease $[15,17]$. A nephropathy susceptibility allele will be observed to be transmitted more often to a Type I diabetic offspring with nephropathy and less often to a Type I diabetic offspring without nephropathy [16]. The TDT is equivalent to a randomized experiment and therefore is resistant to confounding.

We thus have used both case-control association and family-based study designs to assess the C825T variant of the G-protein $\beta 3$ subunit in diabetic nephropathy susceptibility.

\section{Subjects and methods}

Study group. Subjects for the case-control study were recruited through patients participating in an ongoing, large-scale study of the clinical course of microalbuminuria at the Joslin Diabetes Center [18]. During 1991-1993, 50\% of the total Type I diabetic group aged $15-44$ years $(n=1613)$ were screened for nephropathy among whom 201 patients with persistent pro- teinuria or more advanced diabetic nephropathy were identified. Subsequently, screening was extended to all Joslin Type I diabetic patients and the results of both screening programmes were used to select subjects and control subjects for the present study. Type I diabetic patients with persistent proteinuria or end-stage renal disease (ESRD) were considered as nephropathy subjects. Patients without nephropathy, defined as the absence of microalbuminuria with Type I diabetes for 15 or more years, were considered as control subjects. So far 216 nephropathy subjects and 200 control subjects have been enrolled and examined. For the family-based association study, both parents of 152 nephropathy subjects and 90 control subjects from the same group were examined in addition.

Diabetes was considered insulin-dependent if it was diagnosed before age 30 years and treatment with insulin started within 1 year of diagnosis and continued thereafter. Only Caucasian patients with Type I diabetes were recruited.

Examination of study participants. Informed consent was obtained from all Type I diabetic patients and parents who participated in this study and each underwent a detailed history and standardized physical examination. Blood pressure was taken with a standard sphygmomanometer after 10 min sitting and the average of two measurements taken. Hypertension was defined as either systolic blood pressure (SBP) $140 \mathrm{mmHg}$ or more, diastolic blood pressure (DBP) $90 \mathrm{mmHg}$ or more or the use of anti-hypertensive medication. Each participant provided a random urine sample for urinalysis and albumin:creatinine ratio (ACR) determination and blood samples for biochemical analysis and DNA isolation. We measured $\mathrm{HbA}_{1 \mathrm{c}}$ as outlined before [19]. The protocol for the study was approved by the Committee on Human Subjects of the Joslin Diabetes Center.

Diagnosis of diabetic nephropathy. Type I diabetic patients were classified into stages of diabetic nephropathy on the basis of questionnaires, medical records (from the Joslin Diabetes Center and other institutions) and measurements of the urinary ACR. Methods for the ACR determination have been described previously $[18,19]$. Type I diabetic patients without a history of diabetic nephropathy, having an ACR less than $17 \mu \mathrm{g} / \mathrm{mg}$ (for men) or $25 \mu \mathrm{g} / \mathrm{mg}$ (women) were considered normoalbuminuric controls $(n=200)$. These sex-specific values are equivalent to an urinary albumin excretion rate of $30 \mu \mathrm{g} /$ min [19]. Type I diabetic patients with persistent proteinuria were considered as proteinuric subjects $(n=150)$ and those with a renal transplant or on dialysis due to diabetic nephropathy were considered as ESRD subjects $(n=66)$. Persistent proteinuria was diagnosed if a patient had two out of three sequential urinalyses positive based on either reagent strip $1+$ or more (Multistix, Ames Division, Miles Laboratories, Elkhart, Ind., USA) or an ACR $300 \mu \mathrm{g} / \mathrm{mg}$ or more. Type I diabetic patients who had microalbuminuria or intermittent proteinuria were excluded from the study.

Genotyping of G-protein $\beta 3$ subunit C825T polymorphism. The polymorphism in exon 10 of the guanine nucleotide binding protein beta polypeptide 3 (GNB3) gene was detected by the same method as reported previously [13]. Briefly 20-50 ng of genomic DNA was amplified using the following primer pair: forward: 5'-TGACCCACTTGCCACCCGTGC-3', reverse: 5'-GCAGCAGCCAGCGCTGGC-3'. Polymerase chain reaction $(\mathrm{PCR})$ reaction conditions were as described previously [13]. The $268 \mathrm{bp}$ product was restricted with BseD1 (Fermentas, Amherst, New York, USA). The unrestricted 268 bp product represents the $\mathrm{T}$ allele whereas a $\mathrm{C}$ allele was cut into $116 \mathrm{bp}$ and $152 \mathrm{bp}$ fragments. The three genotypes were scored after running on a $2.5 \%$ agarose gel. 
Statistical analysis. Genotype and allele frequency among control subjects and subjects were compared using standard chisquared tests. Continuous variables were compared with Student's $t$-tests. The effect of the three genotypes on DBP and SBP was assessed using a linear regression model with DBP or SBP as the dependent variable. The functional effects of the GNB3 C825T polymorphism have been shown to be associated with carriage of one or two copies of the T allele, i.e. CT or TT genotypes [13]. For the purposes of this study the genotypes are presented as two groups $\mathrm{CC}$ and CT/TT reflecting this functional effect.

The transmission disequilibrium test (TDT) within families examines whether association is due to linkage disequilibrium rather than population stratification $[15,20]$. In the TDT the transmission of alleles from heterozygous parents to offspring is compared with non-transmission with an expected ratio of 50:50 for an allele with no influence on offspring phenotype. Comparison between the observed transmission and the expected proportion of $50 \%$ was done with McNemar's test. The overall comparison of transmitted alleles in the subjects and control subjects was done by a standard chi-squared test.

\section{Results}

Assessment of GNB3 C825T polymorphism in Type I diabetic case-control study. The Type I diabetic group with nephropathy consisted of 216 subjects, 66 of whom had ESRD. The control Type I diabetic subjects $(n=200)$ had normoalbuminuria despite a minimum of 15 years diabetes duration. As expected the total nephropathy group had longer diabetes duration, poorer glycaemic control and higher SBP and DBP compared with the normoalbuminuric group (Table 1). Within the nephropathy group the patients with ESRD were older ( $39 \pm 5$ years vs $36 \pm 7$ years, $p<0.005)$ and had higher SBP $(142 \pm 20 \mathrm{mmHg}$ vs $131 \pm 19 \mathrm{mmHg}, p<0.005)$ than those with proteinuria. The presence of hypertension (defined as SBP $\geq$ $140 \mathrm{mmHg}$ or DBP $\geq 90 \mathrm{mmHg}$ or use of anti-hypertensive medication) was more common in the nephropathy group than in the control group. Blood pressure data was available on 260 parents of nephropathy offspring and 112 parents of control Type I diabetic offspring. Essential hypertension defined as above, was more common in the parents of nephropathy offspring than in the parents of control subjects $(56 \%$ vs $31 \%, p=0.001)$. The presence of parental hypertension was associated with a $2.7-(95 \%$ confidence interval 1.7-4.4) fold increase in risk of nephropathy, based on this study sample.

The $\mathrm{T}$ allele, previously associated with essential hypertension, was present in $30 \%$ of control Type I diabetic subjects and $32 \%$ of subjects with nephropathy. The $\mathrm{T}$ allele frequency was $30 \%$ in the ESRD subset. Expected genotype frequencies from the observed allele frequencies did not deviate from Hardy-Weinberg equilibrium.

There was no significant difference in the frequency of the three genotypes between the Type I diabetic
Table 1. Clinical characteristics of Type I diabetic groups

\begin{tabular}{lll}
\hline & $\begin{array}{l}\text { Type I diabetic } \\
\text { control subjects } \\
(n=200)\end{array}$ & $\begin{array}{l}\text { Type I diabetic } \\
\text { nephropathy subjects } \\
(n=216)^{\mathrm{a}}\end{array}$ \\
\hline $\begin{array}{l}\text { Age (years) } \\
\text { Sex (\% Male) }\end{array}$ & $34 \pm 8$ & $36 \pm 7^{\mathrm{d}}$ \\
$\begin{array}{l}\text { Type I diabetes } \\
\text { duration (years) }\end{array}$ & $24 \pm 6$ & $51 \%$ \\
$\mathrm{HbA}_{1 \mathrm{c}}^{\mathrm{b}}(\%)$ & $8.3 \pm 1.2$ & $27 \pm 7^{\mathrm{d}}$ \\
$\mathrm{SBP}(\mathrm{mmHg})$ & $120 \pm 16$ & $9.3 \pm 1.6^{\mathrm{d}}$ \\
$\begin{array}{l}\text { DBP }\left(\mathrm{mm} \mathrm{Hg}^{\mathrm{d}}\right) \\
\text { Hypertension }\end{array}$ & $72 \pm 9$ & $134 \pm 20^{\mathrm{d}}$ \\
Parental & $11 \%$ & $80 \pm 10^{\mathrm{d}}$ \\
hypertension & $31 \%$ & $60 \% \mathrm{e}^{\mathrm{e}}$ \\
\hline
\end{tabular}

a The nephropathy group consisted of 150 Type I diabetic patients with proteinuria and 66 with ESRD.

b $\mathrm{HbA}_{1 \mathrm{c}}$ values taken over a two year window period prior to recruitment.

c Hypertension defined as SBP $\geq 140 \mathrm{~mm} \mathrm{Hg}, \mathrm{DBP} \geq 90 \mathrm{~mm}$ $\mathrm{Hg}$ or use of anti-hypertensive medication.

d $p<0.0001$, nephropathy subjects vs control subjects.

e $p<0.001$, nephropathy subjects vs control subjects.

Data are means \pm SD

Table 2. Distribution of GNB3 C825T alleles and genotypes in the case-control association study: 200 control subjects with normoalbuminuria and 216 subjects with nephropathy

\begin{tabular}{lll}
\hline & $\begin{array}{l}\text { Type I diabetic } \\
\text { control subjects } \\
(n=200) \\
n(\%)\end{array}$ & $\begin{array}{l}\text { Type I diabetic } \\
\text { nephropathy subjects } \\
(n=216) \\
n(\%)\end{array}$ \\
\hline allele C & $281(70)$ & $294(68)$ \\
allele T & $119(30)$ & $138(32)$ \\
Total chromosomes & 400 & 432 \\
& Total $\chi^{2}(1$ d.f. $)=0.46, p=0.5$ \\
Genotype CC & $102(51)$ & $102(47)$ \\
Genotype CT & $77(39)$ & $90(42)$ \\
Genotype TT & $21(10)$ & $24(11)$ \\
Total subjects & 200 & 216 \\
& Total $\chi^{2}(2$ d.f. $)=0.6, p=0.7$ \\
\hline
\end{tabular}

control group and the Type I diabetic nephropathy subjects (Table 2). The distribution of genotypes in the subset of Type I diabetic nephropathy patients with ESRD $(n=66)$ was not significantly different from either the proteinuric or control Type I diabetic groups: $31(47 \%)$ with CC, 31(47\%)with CT and 4 $(6 \%)$ with the TT genotype.

Combining the genotype groups based on the presence of at least one T allele also showed no significant differences between the groups: in the control group $49 \%$ had the CT/ TT genotype compared with $53 \%$ in the overall nephropathy group $\left(\chi^{2}=0.6, p=0.7\right)$.

There was no effect of the polymorphism on variation in either SBP or DBP when analysed in the neph- 
Table 3. Transmission of the GNB3 alleles from heterozygous parents to Type I diabetic offspring with nephropathy

\begin{tabular}{llll}
\hline & $\begin{array}{l}\text { Tallele } \\
\text { transmitted }\end{array}$ & $\begin{array}{l}\text { Callele } \\
\text { transmitted }\end{array}$ & $\begin{array}{l}p \\
\text { value }^{\mathrm{a}}\end{array}$ \\
\hline $\begin{array}{l}\text { Type I diabetic offspring } \\
\text { with diabetic nephropathy } \\
(n=125)\end{array}$ & $64(51 \%)$ & $61(49 \%)$ & 0.79 \\
\hline
\end{tabular}

a McNemar's test

ropathy and control groups (data not shown). Even when the groups were stratified based on $\mathrm{HbA}_{1 \mathrm{c}}$ ( $\geq 8.1$ ) and duration ( $\geq 25$ years), there was still no difference in the genotype distribution for the C825 $\mathrm{T}$ polymorphism, between subjects and control subjects (data not shown).

Assessment of GNB3 C825T polymorphism in families with Type I diabetic offspring using the transmission disequilibrium test. We investigated the transmission of alleles from heterozygous parents to offspring with Type I diabetes and nephropathy. The T allele was transmitted to $51 \%$ of nephropathy offspring from a total of 125 informative heterozygous parents $(p=0.79)$ (Table 3$)$. T allele transmission to Type I diabetic offspring with ESRD or proteinuria did not differ significantly from $50 \%$ (data not shown). We have also genotyped the families with a control Type I diabetic offspring: the $\mathrm{T}$ allele was transmitted to $44 \%$ of Type I diabetic control offspring from 55 heterozygous parents analysed $(p=0.35)$. These results confirm the case-control association study.

\section{Discussion}

The previous report on the $\mathrm{C} 825 \mathrm{~T}$ polymorphic variant of the B3 subunit of a human G-protein made a case for this gene as a candidate in the predisposition to essential hypertension [13]. In Type I diabetes hypertension occurs almost always in association with proteinuria [21, 22]. Also in many types of family studies, susceptibility to diabetic nephropathy is intimately related to the predisposition to essential hypertension [23]. In this study we have documented, in a large sample size, that parental hypertension is almost twice as prevalent (56\% vs $31 \%$ ) in diabetic nephropathy patients compared with Type I diabetic offspring with normoalbuminuria.

With a large group of Type I diabetic patients, we have found, however, no evidence that the GNB3 gene represents a major predisposition to diabetic nephropathy. This conclusion is based on the results from a large case-control study and the absence of any preferential transmission of C825T alleles to Type I diabetic offspring in families. If this genetic variant has a major role in hypertension susceptibility we would have expected it to be associated with dia- betic nephropathy. What are the possible reasons for the differences between this study and the original report showing its association with essential hypertension?

Firstly, essential hypertension is a polygenic and therefore heterogeneous disorder [24]. Therefore the G-protein $\beta 3$ subunit possibly has a discrete role in the predisposition of a subset of people to hypertension which does not overlap with the predisposition of diabetic nephropathy. Moreover, the enhanced activation of G-proteins described recently in diabetic nephropathy could be secondary to hypertension and not a primary event [12]. There is some evidence for this in the report demonstrating enhanced G-protein activity in cells from Type I diabetic patients [12]. In this study there was a lower response in cells from diabetic nephropathy patients not on anti-hypertensives compared with those on treatment for hypertension [12]. This suggests the difference in G-protein activity could be intrinsic to the pathophysiology of hypertension or secondary to anti-hypertensive treatment and not necessarily a primary abnormality in the pathogenesis of diabetic nephropathy.

Secondly, the findings in the original report on the GN $\beta$-3 polymorphism do not suggest a major role in essential hypertension susceptibility since the absolute differences in the reported case-control group was small [13]. The Tallele frequency was 0.25 in normotensive control subjects and 0.31 in hypertensive subjects. Given the frequency of the $\mathrm{T}$ allele in the normotensive control subjects, almost half the control group carried at least one "hypertension" allele (44\% with CT/TT) and yet had low mean SBP and DBP of 114 and $72 \mathrm{mmHg}$, respectively for their mean age of 56 . The odds ratio conferred by the presence of the CT/TT genotype was 1.4. Based on this and the findings in this study it would appear that the effect of this genetic variant on hypertension is probably minor.

Lastly, the mean age of the normotensive and hypertensive groups in the original report were 56 and 57 years respectively and it is possible that the effect of this gene on blood pressure is expressed in mid-to later life. This possibility can only be addressed by other studies of this variant in essential hypertension groups. In the Type I diabetic patients in this report we have been unable to show any difference in either SBP or DBP based on genotype in either the control or nephropathy groups. It thus seems plausible that the effect of this gene on blood pressure is age dependent and is unlikely to be a factor in the genetic susceptibility to nephropathy in Type I diabetes where onset occurs before middle life.

We cannot exclude that this gene has a minor role in susceptibility to diabetic nephropathy which was not demonstrable in this daraset of over 400 Type I diabetic patients. Given a reference genotype frequency (CC genotype) of 0.5 in the control Type I di- 
abetic group, this dataset would have $80 \%$ power to detect a risk genotype (CT/TT genotype) conferring an odds ratio of 1.7 or greater at the $p=0.05$ level. We therefore consider that this gene is unlikely to be clinically significant in the predisposition to diabetic nephropathy.

The design of this study allows us to investigate the role of candidate genes involved in diabetic nephropathy susceptibility within these families without the effects of confounding due to population stratification. The use of families with a Type I diabetic offspring without nephropathy allows us to exclude excess transmission that may be seen at a Type I diabetes susceptibility locus [16]. Since we have observed no significant deviation in either families with or without diabetic nephropathy, we are confident that transmission of alleles at this polymorphism do not contribute substantially to nephropathy risk. In work with other candidate genes we have found that this TDT based analysis is very sensitive in detecting excess transmission at various other candidate loci studied $[16,25,26]$.

In conclusion, we have found no evidence for a role of the GNB3 C825 T functional variant in the genetic susceptibility to diabetic nephropathy in Type I diabetes, as assessed in a large case-control and family-based association study. In addition, there appears to be no significant effect of this polymorphism on variation in blood pressure in this Type I diabetic group.

Acknowledgements. The study was supported by National Health Institutes grant DK 41526 . D. G. Fogarty is supported by a Peel Travelling Medical Fellowship (London, UK) and a Fulbright Scholarship.

\section{References}

1. United States Renal Data Systems. USRDS 1994 Annual Data Report (1994) Incidence and causes of treated renal disease. Am J Kidney Dis 24[Suppl]S48-S56

2. Borch-Johnsen K, Norgaard K, Hommel E et al. (1992) Is diabetic nephropathy an inherited complication? Kidney Int 41: 719-722

3. Seaquist ER, Goetz FC, Rich S, Barbosa J (1989) Familial clustering of diabetic kidney disease. Evidence for genetic susceptibility to diabetic nephropathy. N Engl J Med 320: 1161-1165

4. Quinn M, Angelico MC, Warram JH, Krolewski AS (1996) Familial factors determine the development of diabetic nephropathy in patients with IDDM. Diabetologia 39: 940-945

5. Viberti GC, Keen H, Wiseman MJ (1987) Raised arterial pressure in parents of proteinuric insulin dependent diabetics. BMJ 295: 515-517

6. Krolewski AS, Canessa M, Warram JH et al. (1988) Predisposition to hypertension and susceptibility to renal disease in insulin-dependent diabetes mellitus. N Engl J Med 318: $140-145$

7. Rosskopf D, Dusing R, Siffert W (1993) Membrane sodium-proton exchange and primary hypertension. Hypertension 21: 607-617
8. Ng LL, Davies JE, Siczkowski M et al. (1994) Abnormal $\mathrm{Na}+/ \mathrm{H}+$ antiporter phenotype and turnover of immortalised lymphoblasts from type 1 patients with diabetic nephropathy. J Clin Invest 93: 2750-2757

9. Trevisan R, Li LK, Messent J et al. (1992) $\mathrm{Na}+/ \mathrm{H}+$ antiport activity and cell growth in cultured skin fibroblasts of IDDM patients with nephropathy. Diabetes 41: 1239-1246

10. Siffert W, Rosskopf D, Moritz A et al. (1995) Enhanced G protein activation in immortalized lymphoblasts from patients with essential hypertension. J Clin Invest 96: 759-766

11. Gutkind JS (1998) The pathways connecting G proteincoupled receptors to the nucleus through divergent mitogen-activated protein kinase cascades. J Biol Chem 273: 1839-1842

12. Pietruck F, Spleiter S, Daul A et al. (1998) Enhanced G protein activation in IDDM patients with diabetic nephropathy. Diabetologia 41: 94-100

13. Siffert W, Rosskopf D, Siffert G et al. (1998) Association of a human G-protein beta3 subunit variant with hypertension. Nat Genet 18: 45-48

14. Lander ES, Schork NJ (1994) Genetic dissection of complex traits. Science 265: 2037-2048

15. Spielman RS, McGinnis RE, Ewens WJ (1993) Transmission test for linkage disequilibrium: the insulin gene region and insulin-dependent diabetes mellitus (IDDM). Am J Hum Genet 52: 506-516

16. Rogus JJ, Moczulski D, Freire MB, Yang Y, Warram JH, Krolewski AS (1998) Diabetic nephropathy is associated with AGT polymorphism T235: results of a family-based study. Hypertension 31: 627-631

17. Marron MP, Raffel LJ, Garchon HJ et al. (1997) Insulin-dependent diabetes mellitus (IDDM) is associated with CTLA4 polymorphisms in multiple ethnic groups. Hum Mol Genet 6: 1275-1282

18. Warram JH, Gearin G, Laffel L, Krolewski AS (1996) Effect of duration of type 1 diabetes on the prevalence of stages of diabetic nephropathy defined by albumin/creatinine ratio. J Am Soc Nephol 7: 930-937

19. Krolewski AS, Laffel LM, Krolewski M, Quinn M, Warram JH (1995) Glycosylated hemoglobin and the risk of microalbuminuria in patients with insulin-dependent diabetes mellitus. N Engl J Med 332: 1251-1255

20. Spielman RS, McGinnis RE, Ewens WJ (1994) The transmission/disequilibrium test detects cosegregation and linkage. Am J Hum Genet 54: 559-560

21. Barzilay J, Warram JH, Bak M, Laffel LM, Canessa M, Krolewski AS (1992) Predisposition to hypertension; Risk factor for nephropathy and hypertension in IDDM. Kidney Int 41: 723-730

22. Christiansen JS (1990) Natural history of hypertension and kidney disease in diabetes. J Hypertens 8: S37-S39

23. Fogarty DG, Krolewski AS (1997) Genetic susceptibility and the role of hypertension in diabetic nephropathy. Curr Opin Nephrol Hypertens 6: 184-191

24. Soubrier F, Lathrop GM (1995) The genetic basis of hypertension. Curr Opin Nephrol Hypertens 4: 177-181

25. Freire MB, Moczulski D, Wantman M, Warram JH, Krolewski AS (1997) Insertion/deletion (I/D) in the ACE gene and diabetic nephropathy (DN): results of a family study. Diabetes 46: 70A (Abstract)

26. Zanchi A, Wantman M, Moczulski D, Warram JH (1998) Genetic susceptibility to diabetic nephropathy in IDDM is related to polymorphism in the endothelial nitric oxide synthase (eNOS) gene. Diabetes 47:A52 (Abstract) 